\title{
Acarbose versus trans- chalcone: comparing the effect of two glycosidase inhibitors on obese mice
}

1 Department of Biology, Science and Research Branch, Islamic Azad University, Tehran, Iran

${ }^{2}$ Endocrinology and Metabolism Research Center, Endocrinology and Metabolism Research Institute, Tehran University of Medical Sciences, Tehran, Iran ${ }^{3}$ National Nutrition and Food Science Research Institute, Shahid Beheshti University of Medical Science, Tehran, Iran ${ }^{4}$ Biosensor Research Center, Endocrinology and Metabolism Molecular-Cellular Sciences Institute, Tehran University of Medical Sciences, Tehran, Iran ${ }^{5}$ Endocrinology and Metabolism Research Center, Endocrinology and Metabolism Clinical Sciences Institute, Tehran University of Medical Sciences, Tehran, Iran

\section{Correspondence to:}

Parichehreh Yaghmaei

Department of Biology,

Science and Research Branch,

Islamic Azad University,

Hesarak - 1477893855 - Tehran, Iran

yaghmaei_p@srbiau.ac.ir

Received on May/16/2014

Accepted on Apr/16/2015
Fatemeh Jalalvand', Mahsa M. Amoli², Parichehreh Yaghmaei', Masoud Kimiagar ${ }^{3}$, Azadeh Ebrahim-Habibij ${ }^{4,5}$

\begin{abstract}
Objective: Acarbose and trans-chalcone are glucosidase inhibitors whose beneficial effects have been demonstrated in diabetes. The present study aimed at investigating their potential effects in obesity. Materials and methods: NMRI male mice $(n=48)$ were subjected to a high fat diet for four weeks, which induced an initial state of obesity. One control group was given normal rodent diet. Obese animals were then switched to normal rodent diet, and divided to four groups $(n=12$ in each): untreated, sham (receiving grape seed oil), and experimental groups receiving acarbose and trans-chalcone $(12 \mathrm{mg} / \mathrm{kg})$ during eight weeks. Body weight, blood glucose and other biochemical parameters including triglycerides (TG), cholesterol, HDL, AST, and ALT were measured, as well as leptin, adiponectin, TNF- $\alpha$, and total antioxidant capacity (TAC). Histological studies were performed on adipose cells and liver tissue samples. Results: All factors were affected in a positive manner by acarbose, save for body weight, blood sugar and leptin levels, on which acarbose effects, although observable, were not statistically significant. Grape seed oil, used as a solvent for trans-chalcone was found to possess significant effect on TG andTAC, and had beneficial effects on other factors including liver enzymes and cholesterol. Trans-chalcone effects were significant on HDL, leptin and ALT. All compounds seemed to be able to affect fat deposition in liver tissue, and decrease the size of adipose tissue cells to some extent. Conclusion: In conclusion, the tested compounds were able to affect lipid accumulation in tissues and influence adipokines, which may result in an enhanced state with regard to inflammation and oxidative stress. Arch Endocrinol Metab. 2015;59(3):202-9
\end{abstract}

\section{Keywords}

Acarbose; chalcone; obesity; adipocyte; adipokine; antioxidant

\section{INTRODUCTION}

$\mathrm{O}$ besity is a chronic metabolic disorder related to energy imbalance resulting from a disproportion between food consumption and physical activity (1). Currently, a high prevalence of obesity is observed worldwide, in both adults and children $(2,3)$. Health practitioners' concern about obesity prevalence is also due to the fact that this condition is accompanied by a wide range of complications including diabetes, nonalcoholic fatty liver disease (NAFLD) (4).

Among various approaches to combat obesity, inhibition of digestive enzymes is a logical solution. Lipase inhibitor orlistat that was used as an anti-obesity drug may cause various side effects including severe liver injury (5), but the search for other lipase inhibitors continues, and other compounds have been reported as potential drugs (6). Glucosidase enzymes such as alpha-amylase are also considered to be an anti-diabetic and anti-obesity target (7). Alpha-amylase inhibitors have been demonstrated to reduce blood sugar levels and cause weight loss (8).

Acarbose, which is a glucosidase inhibitor minimally absorbed from the gastrointestinal tract (9), has been used as a therapeutic supplement in diabetes, since it controls the postprandial rise in blood glucose levels (10). Acarbose is a competitive inhibitor of alpha-glucosidase and has a noncompetitive inhibitory behavior toward alpha-amylase (11). Trans-chalcone structure is a precursor to flavonoids and chalcone compounds and possess a range of therapeutic properties including an- 
tioxidant, cytotoxic, anticancer, antimicrobial, antiprotozoal, antiulcer, antihistaminic and anti-inflammatory (12). We had previously observed the alpha-amylase inhibitory effect of trans-chalcone in vitro (13), and its beneficial effect on streptozotocin-induced diabetic mice (14).

In this study, we aimed at evaluating the effect of trans-chalcone treatment on obese mice, and comparing it with acarbose.

\section{MATERIALS AND METHODS}

\section{Animals}

Male NMRI mice (six weeks old) weighing $25 \pm 5 \mathrm{~g}$ were purchased from the Razi Vaccine and Serum Institute, Karaj, Iran. Mice were exposed to a 12-h light/ dark cycle, and were housed in standard cages. The animal room was maintained at a constant temperature of $25^{\circ} \mathrm{C}$. After one week of adaptation to the conditions, mice were randomly divided into two groups (n $=12$ in each group): normal group (receiving standard rodent diet) and obese group (receiving high-fat diet for eight weeks). The high-fat diet was prepared from a mix of $15 \mathrm{~g}$ of mouse pellet standard chow, $10 \mathrm{~g}$ of roasted ground nut, $10 \mathrm{~g}$ of milk chocolate and $5 \mathrm{~g}$ of sesame crackers. To ten-fold of these ingredients $20 \mathrm{~g}$ roasted sesame was added, resulting into $18 \mathrm{~kJ} / \mathrm{g}$ energy content. In addition, the obese group was fed $240 \mathrm{~g}$ creamy biscuits $(3644 \mathrm{~kJ})$ weekly. The normal group was allowed ad libitum access to standard chow, taking a total of $13 \mathrm{~kJ} / \mathrm{g}$ weekly (15). After eight weeks, all animals were given standard rodent diet, and the obese animals were divided into four groups: sham, obese and two experimental groups. The experimental groups were treated with either acarbose or trans-chalcone $(12 \mathrm{mg} / \mathrm{kg} /$ day) by oral gavage for eight weeks. The obese group did not receive any treatment and the sham groups received grape seed oil which was used as trans-chalcone solvent. Mice were weighed weekly during the eight weeks of treatment. At the end of the experiment, the animals were anesthetized and sacrificed; blood samples were collected and immediately centrifuged at $1500 \mathrm{~g}$ for $10 \mathrm{~min}$ at $4{ }^{\circ} \mathrm{C}$. Serums were then collected and stored at $4{ }^{\circ} \mathrm{C}$ until further analyzes were made. The experimental protocol was performed in accordance with the international guidelines set out in the Guide for the Care and Use of Laboratory Animals (Institute of Laboratory Animal Resources,
1996) and approved by the Animal Ethics Committee of the Science and Research Branch, Azad University, Tehran.

\section{Biochemical parameters}

Serum levels of total cholesterol, triglyceride, HDL, ALT and AST were measured with the use of enzymatic methods (Pars Azmoon, Iran). As a complementary test, blood glucose levels were measured by a glucometer apparatus (ACCU-CHEK, Germany).

\section{Adipokines, TNF-alpha and total antioxidant capacity (TAC)}

Plasma adiponectin, TNF- $\alpha$ and leptin concentration were determined by ELISA (respectively R\&D Systems, USA; Enzo life Science, USA and ALPCO, USA). Plasma total antioxidant capacity (TAC) levels were measured by a colorimetric method (BioVision, USA).

\section{Histological studies}

Sample adipose tissue was fixed in formalin. Smear microscopy of adipose tissue were prepared and stained with hematoxylin and eosin $(\mathrm{H} \& \mathrm{E})$.

\section{Statistical analysis}

The data were statistically analyzed by SPSS. With the use of ANOVA and Tukey's test. Values are reported as mean \pm SD and the level of significance considered at $\mathrm{p}<0.05$.

\section{RESULTS}

\section{Body weight and blood glucose}

After the second eight weeks of the experiment, weight gain of animals was compared. It was found that the untreated obese group gained more weight compared with the other groups, while this weight gain was the least in the control group (Table 1). Treatment with acarbose and chalcone prevented the excessive weight gain (Table 1), but not significantly. The obese group presented elevated blood glucose levels compared to the control group (Table 2). Upon treatment, mice showed lower levels of blood glucose, although the change was not significant. The sham and chalcone groups presented a similar result while acarbose was slightly less effective. 
Table 1. Effects of acarbose and chalcone treatment on body weight (g). Mean body weight of the mice at the week 1 and week 8 of the treatment period. (Week 1: w1, Week 8: w8). Data are reported as mean \pm SD values. P-values are shown in separate columns

\begin{tabular}{|c|c|c|c|c|}
\hline Groups & $\begin{array}{c}\text { Body weight (kg) } \\
\text { Week } 1\end{array}$ & $p(W 1)$ & $\begin{array}{c}\text { Body weight (g) } \\
\text { Week } 8\end{array}$ & p (W8) \\
\hline Control & $37.88 \pm .66$ & $\begin{array}{c}\text { Obese } p=0.32 \\
\text { Sham } p=0.54 \\
\text { Acarbose } p=0.070 \\
\text { Chalcone } p=0.64\end{array}$ & $39.83 \pm .75$ & $\begin{array}{c}\text { Obese } p=0.058 \\
\text { Sham } p=0.71 \\
\text { Acarbose } p=0.49 \\
\text { Chalcone } p=0.58\end{array}$ \\
\hline Obese & $40.95 \pm .46$ & $\begin{array}{c}\text { Control } p=0.32 \\
\text { Sham } p=0.99 \\
\text { Acarbose } p=0.98 \\
\text { Chalcone } p=0.97\end{array}$ & $44.08 \pm .49$ & $\begin{aligned} \text { Control } p & =0.058 \\
\text { Sham } p & =0.54 \\
\text { Acarbose } p & =0.49 \\
\text { Chalcone } p & =0.43\end{aligned}$ \\
\hline Sham & $40.35 \pm .37$ & $\begin{array}{c}\text { Control } p=0.54 \\
\text { Obese } p=0.99 \\
\text { Acarbose } p=0.87 \\
\text { Chalcone } p=0.85\end{array}$ & $41.75 \pm .69$ & $\begin{array}{c}\text { Control } p=0.71 \\
\text { Obese } p=0.54 \\
\text { Acarbose } p=1.000 \\
\text { Chalcone } p=1.000\end{array}$ \\
\hline Acarbose & $41.65 \pm .73$ & $\begin{array}{l}\text { Control } p=0.07 \\
\text { Obese } p=0.98 \\
\text { Sham } p=0.87 \\
\text { Chalcone } p=1\end{array}$ & $41.96 \pm .85$ & $\begin{array}{c}\text { Control } p=0.49 \\
\text { Obese } p=0.49 \\
\text { Sham } p=1.000 \\
\text { Chalcone } p=1.000\end{array}$ \\
\hline Chalcone & $41.76 \pm 1.28$ & $\begin{array}{c}\text { Control } p=0.064 \\
\text { Obese } p=0.97 \\
\text { Sham } p=0.050 \\
\text { Acarbose } p=1\end{array}$ & $41.79 \pm 1.0$ & $\begin{array}{c}\text { Control } p=0.58 \\
\text { Obese } p=0.43 \\
\text { Sham } p=1.000 \\
\text { Acarbose } p=1.000\end{array}$ \\
\hline
\end{tabular}

Table 2. Effects of acarbose and chalcone treatment on blood glucose (mg/dL). Mean blood glucose of the mice at week 4 (W4) and week 8 (W8) of the treatment period is reported. Data are reported as mean \pm SD values. P-values are shown in separate columns

\begin{tabular}{|c|c|c|c|c|}
\hline Groups & $\begin{array}{l}\text { Blood glucose }(\mathrm{mg} / \mathrm{dL}) \\
\text { week } 4\end{array}$ & $p(W 4)$ & $\begin{array}{l}\text { Blood glucose }(\mathrm{mg} / \mathrm{dL}) \\
\text { week } 8\end{array}$ & p (W8) \\
\hline Control & $132 \pm 6.50$ & $\begin{array}{c}\text { Obese } p=0.87 \\
\text { Sham } p=0.57 \\
\text { Acarbose } p=0.98 \\
\text { Chalcone } p=0.096\end{array}$ & $123.50 \pm 2.50$ & $\begin{array}{c}\text { Obese } p=0.89 \\
\text { Sham } p=0.94 \\
\text { Acarbose } p<1.000 \\
\text { Chalcone } p<0.98\end{array}$ \\
\hline Obese & $149.50 \pm .50$ & $\begin{array}{c}\text { Control } p=0.87 \\
\text { Sham } p=0.98 \\
\text { Acarbose } p=0.72 \\
\text { Chalcone } p=0.66\end{array}$ & $135.50 \pm 5.50$ & $\begin{array}{c}\text { Control } p=0.89 \\
\text { Sham } p=0.66 \\
\text { Acarbose } p=0.88 \\
\text { Chalcone } p=0.73\end{array}$ \\
\hline Sham & $159.5 \pm .50$ & $\begin{array}{c}\text { Control } p=0.57 \\
\text { Obese } p=0.98 \\
\text { Acarbose } p=0.44 \\
\text { Chalcone } p=0.38\end{array}$ & $112 \pm 7$ & $\begin{array}{c}\text { Control } p=0.94 \\
\text { Obese } p=0.66 \\
\text { Acarbose } p=0.97 \\
\text { Chalcone } p=0.99\end{array}$ \\
\hline Acarbose & $125.66 \pm 6.98$ & $\begin{array}{c}\text { Control } p=0.98 \\
\text { Obese } p=0.72 \\
\text { Sham } p=0.44 \\
\text { Chalcone } p=1,000\end{array}$ & $121 \pm 14.29$ & $\begin{aligned} \text { Control } p & =1.000 \\
\text { Obese } p & =0.88 \\
\text { Sham } p & =0.97 \\
\text { Chalcone } p & =0.99\end{aligned}$ \\
\hline Chalcone & $123.33 \pm 20.89$ & $\begin{array}{c}\text { Control } p=0.96 \\
\text { Obese } p=0.66 \\
\text { Sham } p=0.38 \\
\text { Acarbose } p=1.000\end{array}$ & $116 \pm 15.62$ & $\begin{array}{c}\text { Control } p=0.98 \\
\text { Obese } p=0.73 \\
\text { Sham } p=0.99 \\
\text { Acarbose } p=0.99\end{array}$ \\
\hline
\end{tabular}

\section{Adipokines}

In comparison with the control group, the untreated obese mice had decreased serum adiponectin levels and increased leptin levels (Figure l A and B). Upon eight-week administration of acarbose and chalcone, a significant increase of adiponectin level was observed for acarbose $(\mathrm{p}<0.01)$, the effect of chalcone was not significant (Figure 1A). On the other hand, treatment with chalcone had a remarkable lowering effect on leptin concentrations $(\mathrm{p}<0.001$ compared to the untreated obese group), while this decrease was not significant in acarbose group.

\section{ALT and AST}

The untreated obese group had increased levels of serum AST and ALT compared with the control group 
(Figure $2 \mathrm{~A}$ and $\mathrm{B}$ ). Upon treatment, although all AST levels were decreased (Figure 2A), the decrease was found to be significant in the acarbose group only $(\mathrm{p}<0.01)$. In the case of ALT, both chalcone and acarbose groups showed significant decrease $(\mathrm{p}<0.05$ and $\mathrm{p}<0.01$ respectively) (Figure $2 \mathrm{~B}$ ).

\section{Lipids}

The serum triglyceride (TG) levels of the untreated obese group were found to be significantly higher than those in the control group, while HDL levels were lower and cholesterol levels were also higher, but not significantly (Figure 3). Acarbose had a significant effect in lowering TG, increasing HDL and lowering cholesterol levels of the treated obese group (Figure 3). Chalcone had a significant effect on HDL only (Figure 3B). Interestingly, the sham group showed also significantly decreased TG levels, in a similar manner to acarbose, and chalcone effect itself was not significant.

A

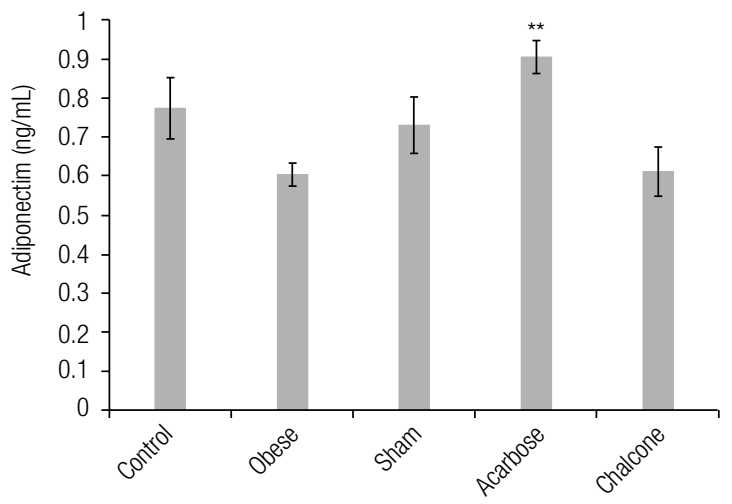

B

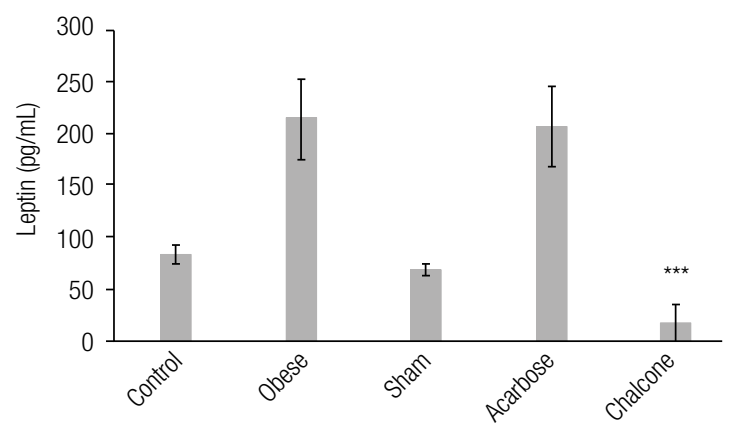

Figure 1. Effect of acarbose and chalcone supplementation on serum adiponectin $(\mathbf{A})$ and leptin $(\mathbf{B})$ in mice ( $n=12$ in each group) after eight weeks of treatment. Data are shown as mean \pm SD. ${ }^{\star *} p<0.01$ compared with the obese group. ${ }^{*} p<0.05$ compared with the obese group.

\section{TAC and TNF- $\alpha$}

Total antioxidant capacity was found to be lower in untreated obese mice, although not significantly (Figure 4A). Acarbose administration increased remarkably the serum TAC while chalcone had no significant effect. The sham group showed also significantly increased TAC (Figure 4A). TNF- $\alpha$ is an inflammatory factor, which was higher in the untreated obese group, although not significantly (Figure 4B). Acarbose was found to significantly reduce serum TNF- $\alpha$ levels $(\mathrm{p}<$ 0.01 ), while in the chalcone group decrease occurred, but was not significant.

\section{Histological studies}

\section{Adipocytes}

Hematoxylin-Eosin (H\&E) staining of the adipose tissues taken from abdominal fat is shown in figure 5. Adipocytes larger size is clearly observed in the untreated

\section{A}

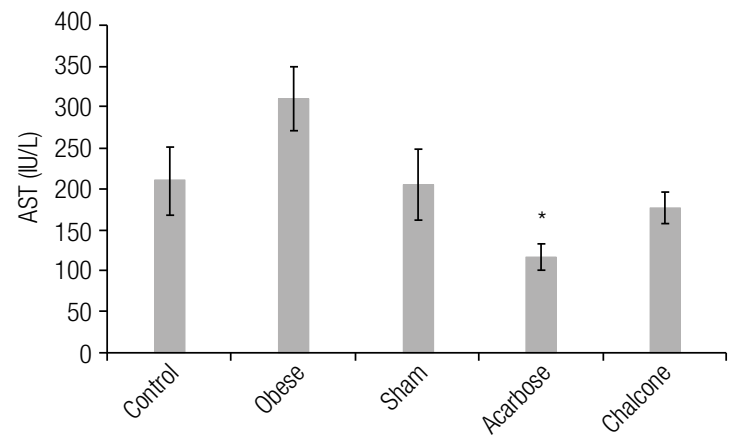

B

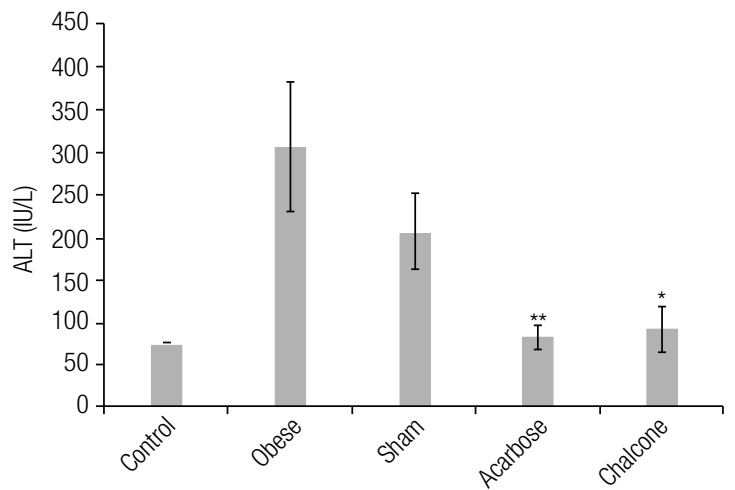

Figure 2. Effect of acarbose and chalcone supplementation on the serum AST (A) and ALT (B) in mice ( $n=12$ in each group) after eight weeks of treatment. Data are shown as mean \pm SD. ${ }^{* *} p<0.01$ compared with the obese group. * $p<0.05$ compared with the obese group. 
obese mice (Figure $5 \mathrm{~B}$ ). Interestingly, both acarbose and chalcone are able to influence the adipose tissue, followed by grape seed oil (administered in the sham group). From the slides, it may be inferred that adipose cells were disrupted by acarbose and chalcone.

\section{Hepatocytes}

In the liver sections of obese animals, fat droplets and multinucleate cells are observed. Furthermore, disordered cell structure is observed when comparing the untreated obese animals tissue with the control group (Figures 6A and 6B). When treated with grape seed oil, chalcone, and acarbose, cell structures become more ordered and the number of two- and multi-nucleated cells is decreased (Figures 6C-6E).

A

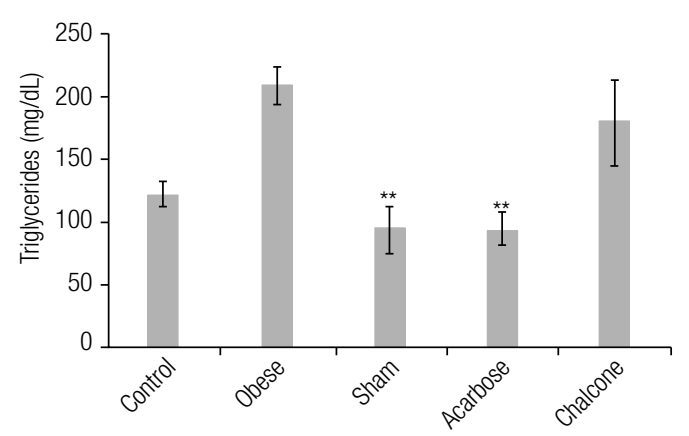

B

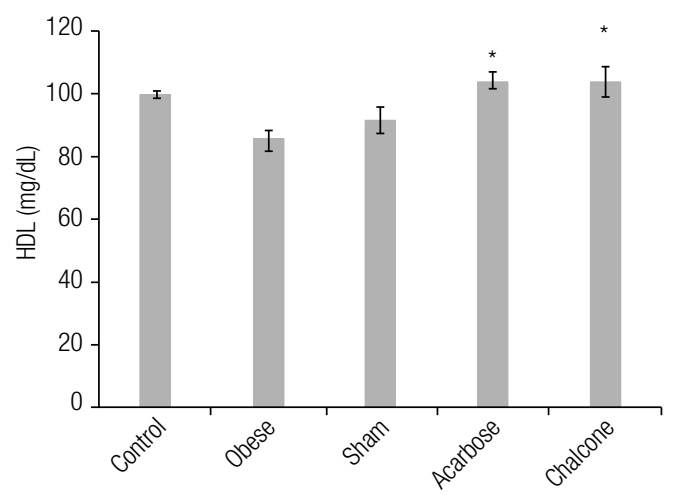

C

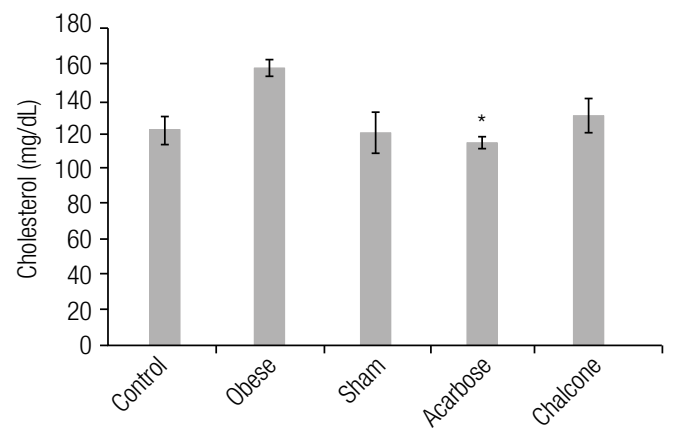

Figure 3. Effect of acarbose and chalcone supplement on serum triglycerides (TG) (A), HDL (B), and cholesterol (C) in mice ( $n=12$ in each group) after eight weeks of treatment. Data are shown as mean \pm SD. ${ }^{\star *} p<0.01$ compared with the obese group. ${ }^{*} p<0.05$ compared with the obese group.
A

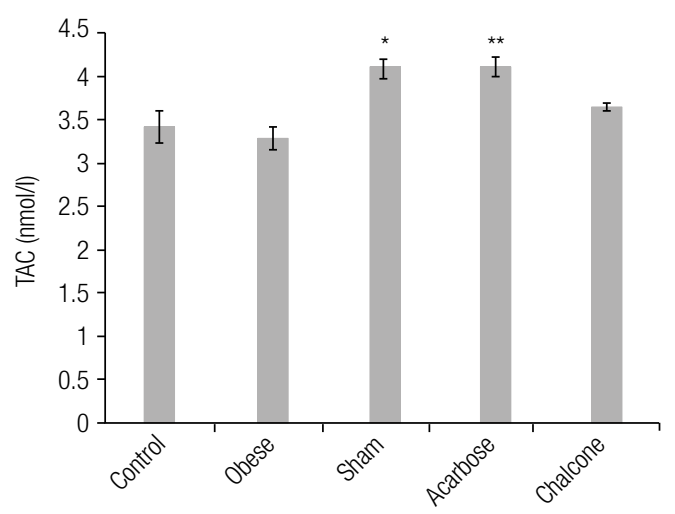

B

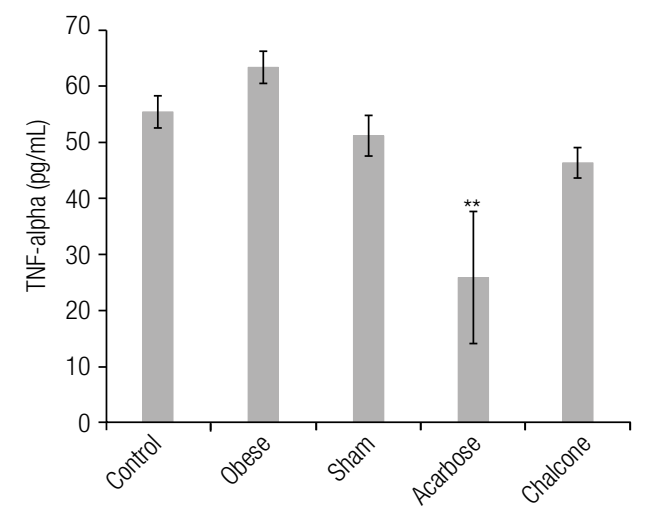

Figure 4. Effects of acarbose and chalcone on serum total antioxidant capacity (TAC) (A) and TNF- $\alpha(\mathbf{B})$ in mice $(n=12$ in each group) after eight weeks of treatment. Data are shown as mean \pm SD. ${ }^{\star *} p<0.01$ compared with the obese group. ${ }^{*} p<0.05$ compared with the obese group.

\section{DISCUSSION}

Acarbose has been used as supplementary therapeutic in diabetes (10), could be envisaged as a potential antiobesity compound as other alpha-amylase inhibitors. Trans-chalcone, on the other hand, is relatively less studied as it is a basic polyphenolic structure: usually, studies are done on its derivatives (16). However, with regard to its alpha-amylase inhibitory effect (13), we thought it interesting to be compared with the wellknown acarbose.

The high fat diet which was used here induced an initial state of obesity in mice. After that, all mice were fed normal rodent diet, so the compounds effects that we have observed are in fact additional to a switch to a normal diet. In some instances, the grape seed oil that had been used as trans-chalcone solvent has a more pronounced effect than chalcone itself. Grape seed oil has been indeed reported to have beneficial effect in overweight and obese patients (17). Concerning weight loss, acarbose, grape seed oil and trans-chalcone treated groups were all showing a more moderate in- 

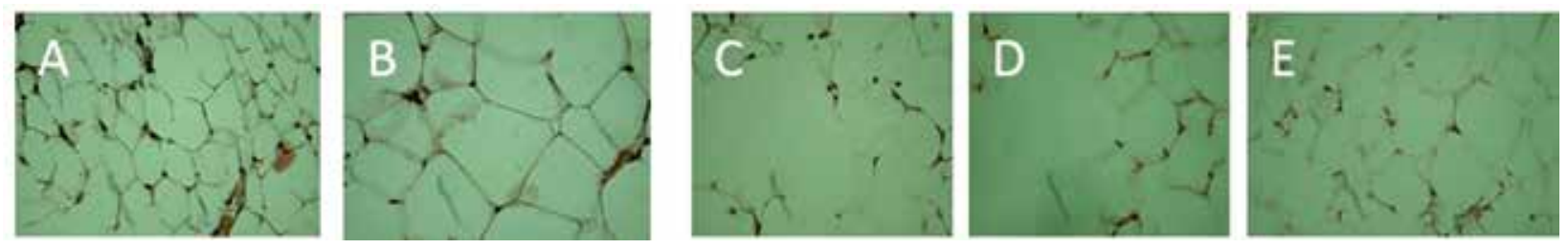

Figure 5. Effect of acarbose and chalcone on adipose tissue: representative H\&E stained sections of perinephric adipose tissue from (A) control group, (B) obese group, (C) acarbose group, (D) chalcone group and (E) sham group after at eight weeks of treatment.
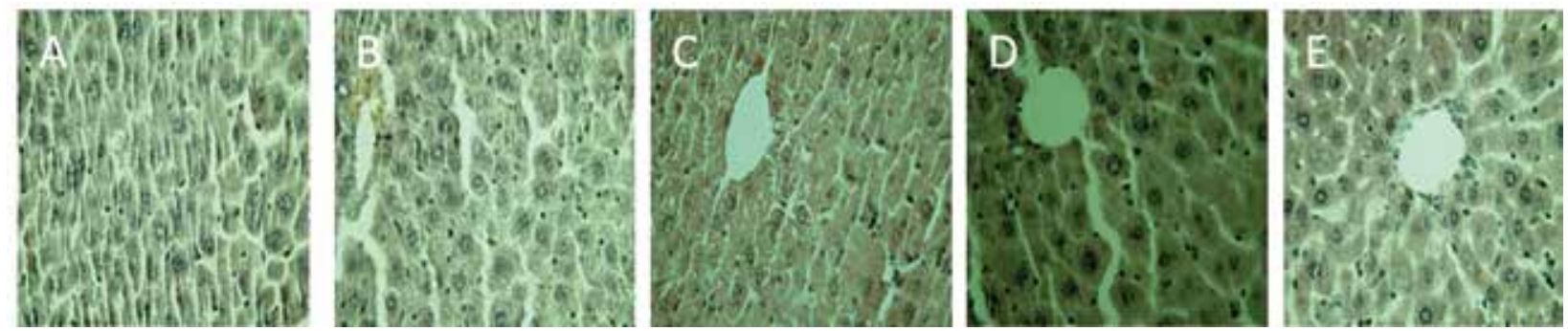

Figure 6. Effect of acarbose and chalcone on liver tissue representative H\&E stained sections of liver tissue from (A) control group, (B) obese group, (C) sham group, (D) chalcone group and (E) acarbose group after at eight weeks of treatment.

crease in weight gain, compared with the untreated group. With regard to the fact that the control group was also gaining weight, this effect could be interpreted as some weight loss. In this case, trans-chalcone may have not been effective, since its effect was similar to grape seed oil.

While an obvious effect of treatment with high-fat diet and the resulting obesity is an altered lipid profile, the potential of compounds in restoring normal values would be of interest. Acarbose was successful with regard to TG and cholesterol levels, while grape seed oil was effective regarding TG and chalcone itself had an effect on HDL levels. Acarbose has been reported to possess beneficial effects on the lipid profile of type 2 diabetes patients (18), and to be able to decrease TG in obese patients with hypertension (with no effect on LDL and HDL) (19). Grape seed oil has been observed to have an effect on decreasing the fat content of other animals bodies (lambs) (20). While more studies are necessary to clarify the exact mechanism of action, we could hypothesize these effects to be related to phenolic compounds that are present in grape seed oil (21). Polyphenolic compounds that are structurally related to chalcone, including flavonoids (22) and coumarin chalcones (23) have been reported to improve lipid profile in high-fat fed or hyperlipidemic animals. Interestingly, the used compounds are also able to act directly on the adipose cells, which presented altered morphology in the treated animals, and chalcone itself seems to pos- sess an independent effect (i.e, independent from grape seed oil).

Levels of the adipokines leptin and adiponectin, which are considered to be therapeutic targets/tools in obesity (24), were also observed to be affected by these compounds. In our study, acarbose was found to increase adiponectin levels in the treated obese rats, which is in accordance with previous reports concerning diabetic patients (25) and diabetic obese rats (26). In our study, leptin levels were not significantly affected by acarbose, which is in contrast with the previously mentioned reports, but it should be noted that in both reports, acarbose had been chronically administered for three months, while our treatment period was eight weeks. The effect of acarbose on adipokines may be linked with its ability to increase insulin sensitivity (27). On the other hand, we have observed a lowering effect of chalcone on leptin levels, which does not seem to have been reported yet for the chalcone core itself, but some flavonoids have been observed to affect adipokines, via a pathway which may be dependent (28) or independent (29) to PPAR $\gamma$. There is also a study performed on naringenin chalcone (composed of a flavonoid and the chalcone moiety), which indicates that this compound induces adiponectin secretion again via PPAR $\gamma$ activation (30).

Overall, these results are indicative of a beneficial effect of the tested compounds on body fat at several levels, which is also seen in liver cells. Fatty liver is 
present in obese patients and may lead to toxicity and complications (31). As a consequence to obesity and the subsequent liver disorder, ALT and AST levels may become elevated (32), and these two factors are even considered as supplementary risk factors for metabolic syndrome that could be detected from childhood (33). Both acarbose and chalcone influenced the levels of ALT in a significant manner, and their beneficial effect is also observable on liver tissue. There is also an association between adipokine levels and the occurrence of fatty liver and elevated ALT levels (34).

Since obesity is accompanied with an inflammatory state (and increase of inflammatory cytokines) (35), the reduction of these factors by potential anti-obesity compounds could be an indicator of their efficacy in controlling the multiple manifestations of the disease. In our study, obese rats showed increased levels of TNF-alpha, while all tested compounds resulted in some degree of TNF-alpha decrease, but only acarbose effect was significant. It may also be noted that these could be indirect effects of the compounds, since adipokines leptin and adiponectin may also influence TNF-alpha levels (36). The inflammatory process that occurs in obesity is also associated with oxidative stress, which is now considered to be a common factor between obesity, diabetes and breast cancer (37). In our study, obese rats showed a moderate decrease in the antioxidant capacity, while acarbose and grape seed oil were able to increase the antioxidant capacity in a significant manner, and chalcone effect is moderate. Polyphenols could prevent the oxidative damage that occurs as a consequence of high fat diet (38). Concerning acarbose, a study conducted on diabetic patients has not found any beneficial effect of acarbose on oxidative stress (39), while another study suggests a possible capability of acarbose in reducing oxidative stress by increasing hydrogen production in the digestive tract (40).

In conclusion, our study has demonstrated that acarbose has a beneficial effect on the adverse effects of obesity, and a moderate effect on weight. Previous reports on acarbose are mostly related to its use in diabetes or obesity cases in which diabetic state is present. Since acarbose is observed to affect adipose tissue, lipid levels, adipokines, and liver enzymes in a relatively limited time period, it may be possible to elicit a better response upon its use over more than two months. Chalcone, which has a basic polyphenolic structure, is also shown to have an effect on HDL, leptin, adipose tissue and ALT. It could be suggested that chalcone derivatives may thus be potentially effective candidates in obesity treatment. Finally, the marked effect of grape seed oil in attenuation of obesity consequences is of interest and is worth being more investigated.

Acknowledgments: this study has been partially supported by the Endocrinology and Metabolism Research Institute of Tehran University of Medical Sciences.

Disclosure: no potential conflict of interest relevant to this article was reported.

\section{REFERENCES}

1. Isganaitis E, Lustig RH. Fast food, central nervous system insulin resistance, and obesity. Arterioscler Thromb Vasc Biol. 2005;25(12):2451-62.

2. Rivera JA, de CossioTG, Pedraza LS, AburtoTC, SanchezTG, Martorell R. Childhood and adolescent overweight and obesity in Latin America: a systematic review. Lancet Diabetes Endocrinol. 2014;2(4):321-32.

3. Kelishadi R, Haghdoost AA, Sadeghirad B, Khajehkazemi R. Trend in the prevalence of obesity and overweight among Iranian children and adolescents: A systematic review and meta-analysis. Nutrition. 2014;30(4):393-400.

4. Musso G, Paschetta E, Gambino R, Cassader M, Molinaro F. Interactions among bone, liver, and adipose tissue predisposing to diabesity and fatty liver. Trends in molecular medicine. 2013;19(9):522-35.

5. Umemura T, Ichijo T, Matsumoto A, Kiyosawa K. Severe hepatic injury caused by orlistat. Am J Med. 2006;119(8):e7.

6. Gras J. Cetilistat for the treatment of obesity. Drugs Today (Barc). 2013;49(12):755-9.

7. Marrelli M, Loizzo MR, Nicoletti M, Menichini F, Conforti F. In vitro investigation of the potential health benefits of wild Mediterranean dietary plants as anti-obesity agents with alpha-amylase and pancreatic lipase inhibitory activities. J Sci Food Agric. 2014;94(11):2217-24.

8. Barrett ML, Udani JK. A proprietary alpha-amylase inhibitor from white bean (Phaseolus vulgaris): a review of clinical studies on weight loss and glycemic control. Nutr J. 2011;10:24.

9. Ahr HJ, Boberg M, Krause HP, Maul W, Muller FO, Ploschke HJ, et al. Pharmacokinetics of acarbose. Part I: Absorption, concentration in plasma, metabolism and excretion after single administration of [14C]acarbose to rats, dogs and man. Arzneimittelforschung. 1989;39(10):1254-60.

10. Krentz AJ, Bailey CJ. Oral antidiabetic agents: current role in type 2 diabetes mellitus. Drugs. 2005;65(3):385-411.

11. Kim MJ, Lee SB, Lee HS, Lee SY, Baek JS, Kim D, et al. Comparative study of the inhibition of alpha-glucosidase, alpha-amylase, and cyclomaltodextrin glucanosyltransferase by acarbose, isoacarbose, and acarviosine-glucose. Arch Biochem Biophys. 1999;371(2):277-83.

12. Sahu NK, Balbhadra SS, Choudhary J, Kohli DV. Exploring pharmacological significance of chalcone scaffold: a review. Curr Med Chem. 2012;19(2):209-25.

13. Najafian M, Ebrahim-Habibi A, Hezareh N, Yaghmaei P, Parivar K, Larijani B. Trans-chalcone: a novel small molecule inhibitor of mammalian alpha-amylase. Mol Biol Rep. 2011;38(3):1617-20. 
14. Najafian M, Ebrahim-Habibi A, Yaghmaei P, Parivar K, Larijani B. Core structure of flavonoids precursor as an antihyperglycemic and antihyperlipidemic agent: an in vivo study in rats. Acta Biochim Pol. 2010;57(4):553-60.

15. Banakar F, Parivara K, Yaghmaeia P, Mohseni-Kouchesfehanib $\mathrm{H}$. The effects of embryo/neonate exposure to Orlistat in NMRImouse strain. Ann Biol Res. 2013;4(6):300-11.

16. Bukhari SN, Jasamai M, Jantan I. Synthesis and biological evaluation of chalcone derivatives (mini review). Mini Rev Med Chem. 2012;12(13):1394-403.

17. Irandoost $\mathrm{P}$, Ebrahimi-Mameghani M, Pirouzpanah S. Does grape seed oil improve inflammation and insulin resistance in overweight or obese women?. Int J Food Sci Nutr. 2013;64(6):706-10.

18. Monami M, Vitale V, Ambrosio ML, Bartoli N,Toffanello G, Ragghianti B, et al. Effects on lipid profile of dipeptidyl peptidase 4 inhibitors, pioglitazone, acarbose, and sulfonylureas: meta-analysis of placebo-controlled trials. Adv Ther. 2012;29(9):736-46.

19. Rachmani R, Bar-Dayan Y, Ronen Z, Levi Z, Slavachevsky I, Ravid $M$. The effect of acarbose on insulin resistance in obese hypertensive subjects with normal glucose tolerance: a randomized controlled study. Diabetes Obes Metab. 2004;6(1):63-8.

20. Bodkowski R, Patkowska-Sokola B. Reduction of body fatness and meat fat content in lambs by supplementing their diet with isomerised grapeseed oil. Anim Sci Pap Rep. 2013;31(3):229-38.

21. Bail S, Stuebiger G, Krist S, Unterweger H, Buchbauer G. Characterisation of various grape seed oils by volatile compounds, triacylglycerol composition, total phenols and antioxidant capacity. Food Chemistry. 2008;108(3):1122-32.

22. Wang JO, Li J, Zou YH, Cheng WM, Lu C, Zhang L, et al. Preventive effects of total flavonoids of Litsea coreana leve on hepatic steatosis in rats fed with high fat diet. J Ethnopharmacol. 2009;121(1):54-60.

23. Sashidhara KV, Palnati GR, Sonkar R, Avula SR, Awasthi C, Bhatia G. Coumarin chalcone fibrates: a new structural class of lipid lowering agents. Eur J Med Chem. 2013;64:422-31.

24. Bluher M. Adipokines - removing road blocks to obesity and diabetes therapy. Mol Metab. 2014;3(3):230-40.

25. Shimazu T, Inami N, Satoh D, Kajiura T, Yamada K, Iwasaka T, et al. Effect of acarbose on platelet-derived microparticles, soluble selectins, and adiponectin in diabetic patients. JThromb Thrombolysis. 2009;28(4):429-35.

26. Perez C, Fernandez-AgulloT, De Solis AJ, Ros M, Andres A, Carrascosa JM. Effects of chronic acarbose treatment on adipocyte insulin responsiveness, serum levels of leptin and adiponectin and hypothalamic NPY expression in obese diabetic Wistar rats. Clin Exp Pharmacol Physiol. 2008;35(3):256-61.

27. Rosen ED, Spiegelman BM. Adipocytes as regulators of energy balance and glucose homeostasis. Nature. 2006;444(7121):847-53.
28. Ding $L$, Jin $D$, Chen $X$. Luteolin enhances insulin sensitivity via activation of PPARgamma transcriptional activity in adipocytes. $J$ Nutr Biochem. 2010;21(10):941-7.

29. Wein S, Behm N, Petersen RK, Kristiansen K, Wolffram S. Quercetin enhances adiponectin secretion by a PPAR-gamma independent mechanism. Eur J Pharm Sci. 2010;41(1):16-22.

30. Horiba T, Nishimura I, NakaiY, Abe K, Sato R. Naringenin chalcone improves adipocyte functions by enhancing adiponectin production. Mol Cell Endocrinol. 2010;323(2):208-14.

31. Schaffer JE. Lipotoxicity: when tissues overeat. Current opinion in lipidology. 2003;14(3):281-7.

32. Elizondo-Montemayor L, Ugalde-Casas PA, Lam-Franco L, Bustamante-Careaga $H$, Serrano-Gonzalez M, Gutierrez NG, et al. Association of ALT and the metabolic syndrome among Mexican children. Obes Res Clin Pract. 2014;8(1):e79-87.

33. Mohammadi F, Qorbani M, Kelishadi R, Baygi F, Ardalan G, Taslimi M, et al. Association of Cardiometabolic Risk Factors and Hepatic Enzymes in a National Sample of Iranian Children and Adolescents: The CASPIAN-III Study. J Pediatr Gastroenterol Nutr. 2014;58(4):463-8.

34. Burgert TS, Taksali SE, Dziura J, Goodman TR, Yeckel CW, Papademetris $X$, et al. Alanine aminotransferase levels and fatty liver in childhood obesity: associations with insulin resistance, adiponectin, and visceral fat. J Clin Endocrinol Metab. 2006;91(11):4287-94.

35. Trayhurn P, Wood IS. Adipokines: inflammation and the pleiotropic role of white adipose tissue. The British journal of nutrition. 2004;92(3):347-55.

36. Bastard J-P, Maachi M, Lagathu C, Kim MJ, Caron M, Vidal H, et al. Recent advances in the relationship between obesity, inflammation, and insulin resistance. European cytokine network. 2006;17(1):4-12.

37. Crujeiras AB, Díaz-Lagares A, Carreira MC, Amil M, Casanueva FF. Oxidative stress associated to dysfunctional adipose tissue: a potential link between obesity, type 2 diabetes mellitus and breast cancer. Free Radic Res. 2013;47(4):243-56.

38. Charradi K, Elkahoui S, Karkouch I, Limam F, Ben Hassine F, EI May MV, et al. Protective effect of grape seed and skin extract against high-fat diet-induced liver steatosis and zinc depletion in rat. Dig Dis Sci. 2014;59(8):1768-78.

39. Wang JS, Lin SD, Lee WJ, Su SL, Lee IT, Tu ST, et al. Effects of acarbose versus glibenclamide on glycemic excursion and oxidative stress in type 2 diabetic patients inadequately controlled by metformin: a 24-week, randomized, open-label, parallel-group comparison. Clinical therapeutics. 2011;33(12):1932-42.

40. Zhang DQ, Zhu JH, Chen WC. Acarbose: a new option in the treatment of ulcerative colitis by increasing hydrogen production. African journal of traditional, complementary, and alternative medicines: AJTCAM / African Networks on Ethnomedicines. 2012;10(1):166-9. 